Please send trade news information and illustrations to Arveen Bajaj at the $B D J$, Nature Publishing Group, The Macmillan Building, 4-6 Crinan Street, London N1 9XW. Trade news is provided as a service to readers using text and images from the manufacturer, supplier or distributor and does not imply endorsement by the BDJ. Normal and prudent research should be exercised before purchase or use of any product mentioned.

\section{Superior mechanical strength}

Kerr is expanding its Premise Mini Kit by adding the CompoRoller, Kerr's innovative composite modelling instrument. This combination allows you to model the Premise 3-filler composite with an 84\% filler load with better control, speed and precision.

In addition, Premise's non-sticky handling and superior mechanical strength, coupled with the CompoRoller's unique action and assortment of tips, allows you to contour the composite quickly in thin, even layers, minimising finishing and polishing times.

The Premise Mini Kit and CompoRoller is available in both Unidose or Syringe delivery and contains all the tools needed for a direct composite restoration.

The kit contains three shades of Premise, one CompoRoller handle, 20 CompoRoller Tips, one Optibond Solo Plus 5ml, one Etching Gel syringe and 50 Applicator Tips.

Reader response number 50

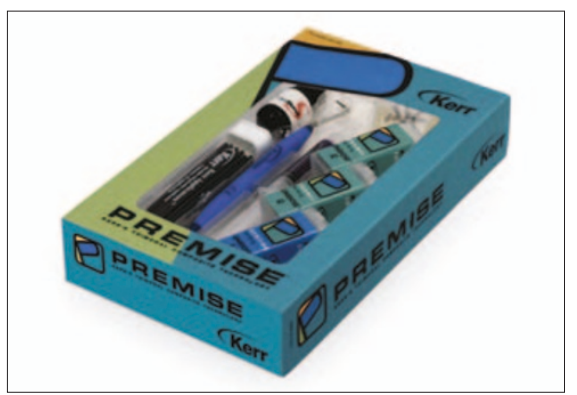

\section{Special offer}

Quick setting restorative Snappy, is ideal for children as it has no unpleasant after taste, does not shrink, adheres to dentine and enamel, releases fluoride and is resistant to saliva as soon as the cavity is filled. Until the end of September, you can get a 'buy one get second pack for £18.00' offer for the Snappy $10 \mathrm{~g} / 7 \mathrm{ml}$ pack in Natural White. The usual price is $£ 26.70$.

Reader response number 52

\title{
New gel launched
}

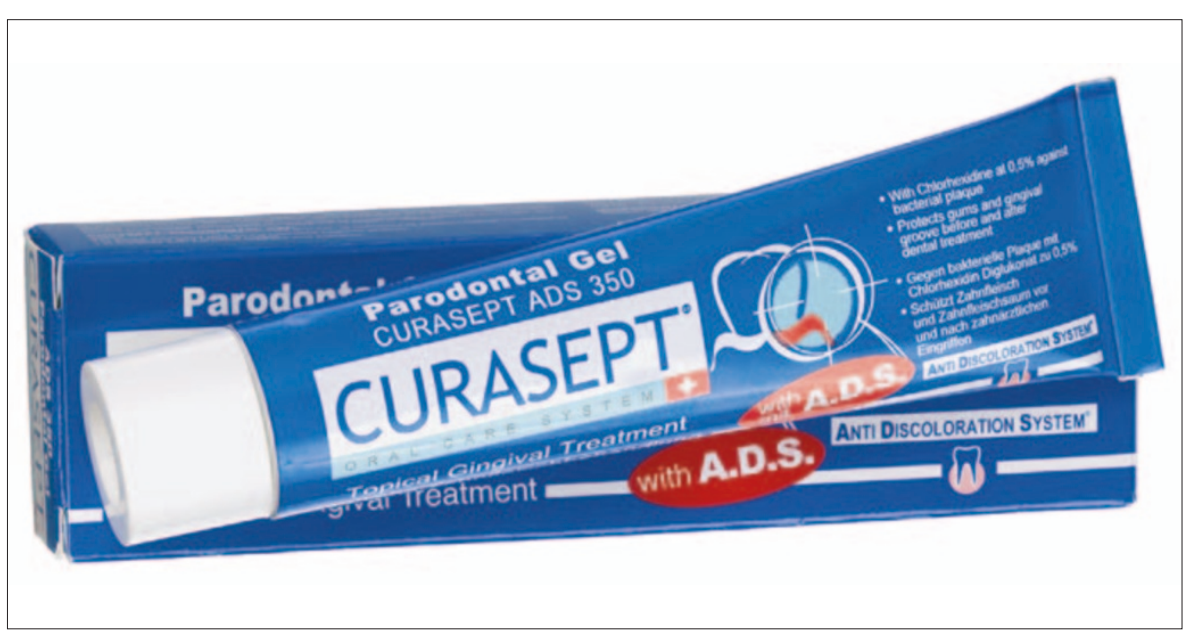

Curaprox has announced the addition of Curasept Gel, a new oral hygiene product, to the Curasept portfolio. Curasept Gel offers all the benefits of Curasept Mouth Rinse but in a gel.

It contains $0.5 \%$ chlorhexidine, is intended for short-term, intensive use and offers effective protection against plaque and caries. The gel is alcohol-free and also has the ADS System which greatly reduces tooth discolouration and the unpleasant changes in taste perception associated with traditional chlorhexidine products. The product offers patients who would otherwise avoid chlorhexidine products the benefits of chlorhexidine in a more acceptable form. The makers add that Curasept Gel will help to prevent posttreatment and post-operative complications when used before or after dental treatment, including endodontic and implant procedures.

Reader response number 51

\section{Full multimedia integration}

For the month of October, Castellini are offering their popular state of the art technology Logos Junior dental unit, with full multimedia integration, with a free Castellini Puma Eli Air integrated package, ideal for a second surgery, making a saving of $£ 9,250$.

The Logos Junior dental unit includes the new Implantor LF 50,000 RPM, Brushless Micromotor \& Videor Intra Oral Camera. The Puma Eli offers extreme versatility and flexibility proving to be a system that can be completely tailored to your needs. A basic dental device that combines technology with the most advanced solution for controlling the risk of

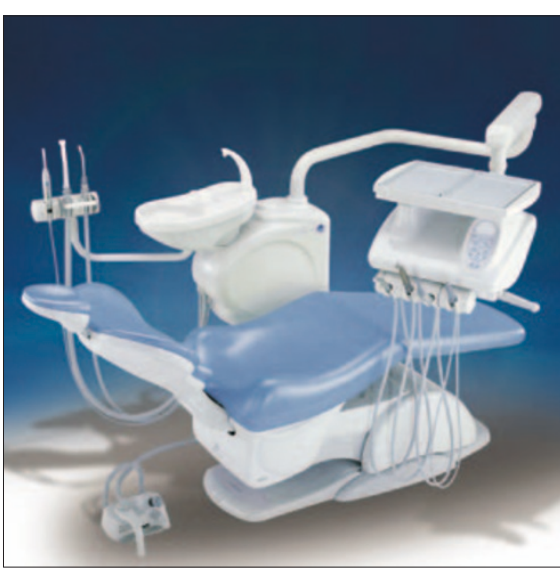

cross-infection, the Puma can be perfectly integrated into any clinical setting.

For more information visit www. castellini.com.

Reader response number 53 


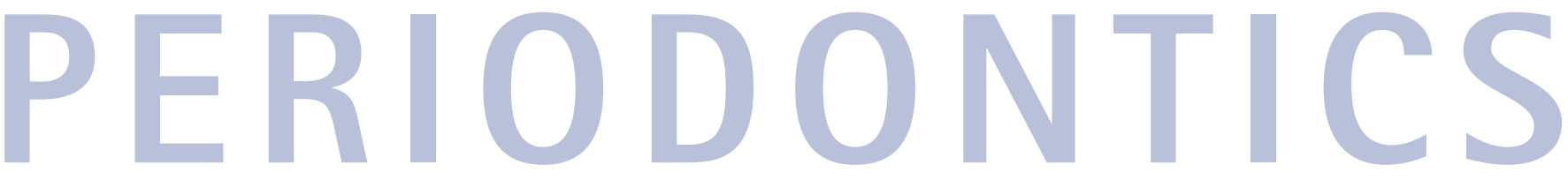

\section{Treatment of chronic periodontitis}

Periostat, distributed by Alliance Pharmaceuticals, is one of the latest products to be introduced to the dental market for the treatment of chronic periodontitis.

It is an orally administered tablet containing a formulation of $23.08 \mathrm{mg}$ doxycycline hyclate. Designed to be taken twice a day as an adjunct to scaling and root planning (SRP), Periostat increases clinical attachment level gain and reduces probing depths in patients with chronic periodontitis.

The duration of treatment with Periostat, a prescription only medicine, will depend on the individual case but is recommended to be at least three months, and its use is approved for up to nine months to suppress the destructive collagenase enzymes and help stabilise the periodontium.

Periostat is not intended to eliminate the need for clinical interventions or procedures that reduce the bacterial load in the periodontal pocket. It is an adjunctive therapy, and is the only approved product formulated specifically to suppress the tissue destroying enzymes primarily responsible for the breakdown of the periodontium.

Reader response number 55

\section{Spread the cost}

The new PerioChip 20 pack from Dexcel Dental is designed to help practices effectively treat more patients with periodontitis. In a special deal, Dexcel are offering various ways to save $25 \%$. You do not have to buy multiple packs all at once. If you sign up to the Frequent User Option you can spread the cost, remove the hassle of ordering and instantly make a saving. Those not keen on signing up can still save money with the rebate offer.

Reader response number 56

\section{Anti-inflammatory action}

Dentomycin used in conjunction with scaling and root planning (SRP) achieves a marked reduction in bacteria in patients with periodontal disease, according to the manufacturers. Now Dentomycin can offer added benefits, as it also produces a positive effect on tissue and bone generation by inhibiting destructive collagenases, exerting a positive anti-inflammatory action and promoting connective tissue attachment.

Available from Blackwell Supplies, Dentomycin is a periodontal gel containing 2\% minocycline, an antibiotic well known for its ability to eliminate key periodontal pathogens.

Dentomycin binds to the tooth surface and is released slowly, attacking the bacteria and maintaining the low levels achieved through mechanical debridement. Minocycline is known to carry a minimal risk of provoking bacterial resistance, allowing patients to benefit from the treatment ensuring optimal results.

The makers claim it can effectively

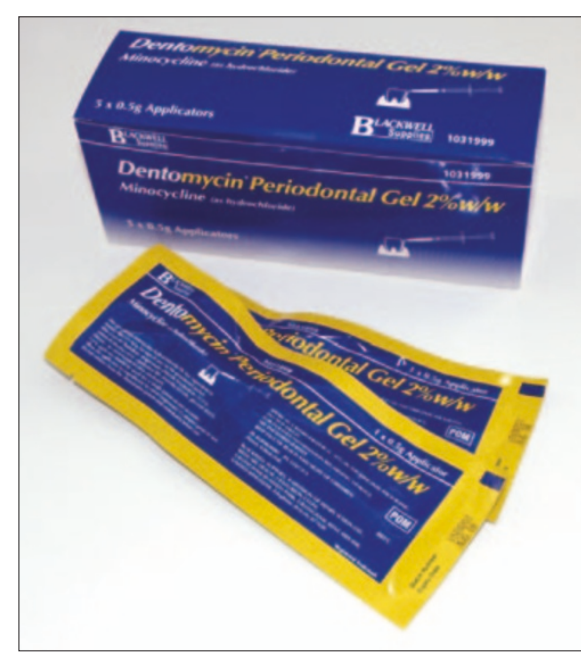

reduce pocket depths and bacteria levels while actively promoting periodontal healing. It is supplied in easy to use, pre-filled applicators that allow the delivery of the gel directly into the periodontal pocket for immediate effect.

Reader response number 54

\section{Technologically advanced laser}

DMDS are proud to announce their brand new laser, the Soft Tissue Diode Laser.

The Soft Tissue Diode Laser weights just $2.5 \mathrm{~kg}$ and is small enough to fit into a briefcase making it easy to move from surgery to surgery.

The applications are numerous, from gingivectomy and crown lengthening to laser curettage with everything else in between including, operculectomy, oral papillectomy, exposure of interrupted teeth, crown lengthening, removal of fibromas and tissue retraction for impression.

The laser is directed through a jacketed glass clad silica fibre and both this and the handpiece are fully autoclaveable for complete sterilisation. With a wavelength of $808(+/-) 5$ nanometers and 2.5 watts of power the Soft Tissue Diode Laser is

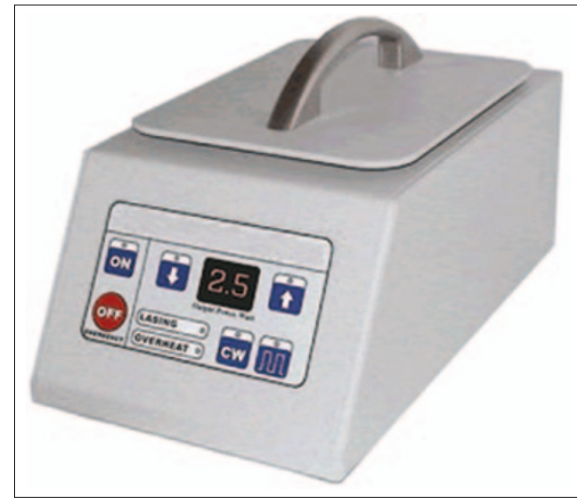

extremely effective. You can choose from either a continuous wave or pulsed depending upon your chosen application giving you more versatility.

Reader response number 57 


\section{Individual sample} pack

Molar's TePe sample packs have proved so popular that Molar is now making them available for practitioners to purchase.

Each pack contains eight TePe interdental brushes - one of each size from the range from the smallest (Pink $0.4 \mathrm{~mm}$ ), through to the largest, (Grey $(1.3 \mathrm{~mm})$. Each pack also comes with a travel cap. The sample pack is ideal for those patients with a number of different sized interproximal spaces who need to be able to try a selection of sizes before deciding on which they feel most comfortable with. The cost per pack is $£ 1.89$ which is 24 pence per brush. However if you prefer to size TePe brushes on patients yourselves, then the TePe Surgery refill pack offers even better value, working out at just 19 pence each.

This pack contains 32 brushes including one travel cap per brush (excluding grey) and 12 patient information leaflets. Both the packs are available from most dental wholesalers. For further information visit www.molarltd.co.uk Reader response number 59

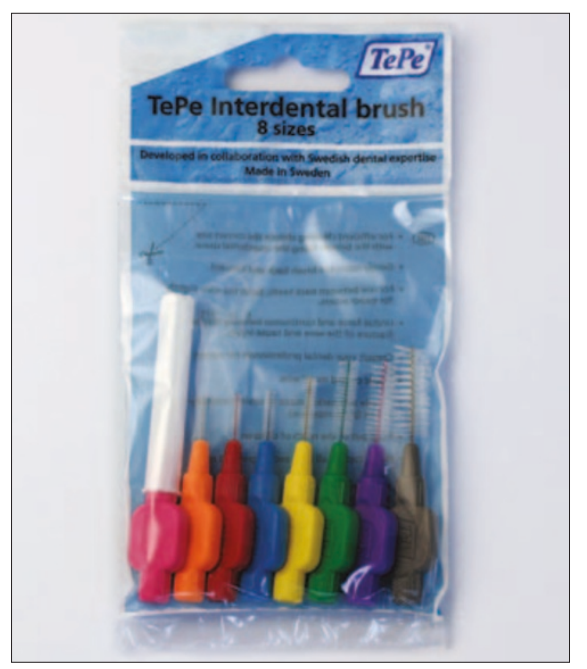

\section{Low-splatter formula}

Nupro prophy paste from Dentsply has a low-splatter formula which makes it easy to use as less splatter means less cleaning, and an easier working environment. It

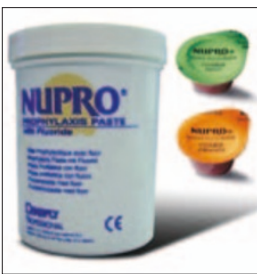
is available in a tangy orange flavour or a fresh mint in both unit-dose cups (for better cross infection control) and in larger, multi-use tubs. It is supplied in a range of three grit sizes ensuring you a range of cleaning and stain removing options. Reader response number 62

\section{Instrument with longer reach}

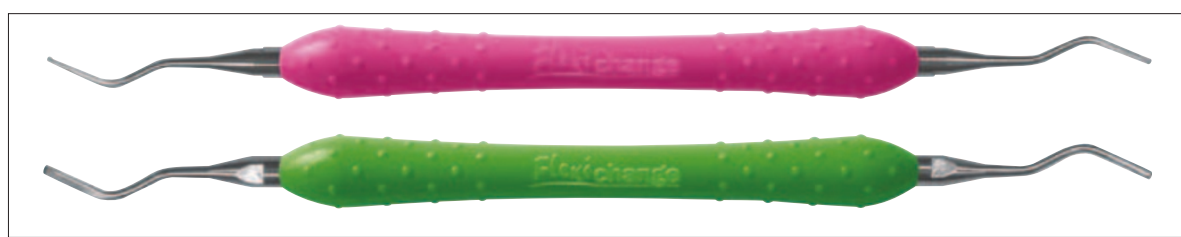

For effective periodontal therapy, it is essential to leave the pocket as clean as possible, but this can be complex with a really deep pocket. The Dentsply Ash WonderHoe has been designed with a longer reach than the average hoe and a slightly extended curvature.

The longer reach and the slightly curved tip means the WonderHoe follows the

\section{Multi-layer diamonds}

Dentsply Ash Instruments' Hi-Di burs are made to an exacting standard, to ensure consistency that will help prolong the longevity of your handpiece. The bur head has evenly distributed, multi-layer diamonds, so they remain sharp throughout their life.

All Ash diamond burs undergo full inspection (under $20 \mathrm{x}$ magnification) prior to sale, and only use real diamonds, which have more cutting facets than synthetic diamonds.

The range is packaged in a user-friendly matchbook design, which allows for simple access, and safe storage.

Reader response number 60

\section{Close magnification}

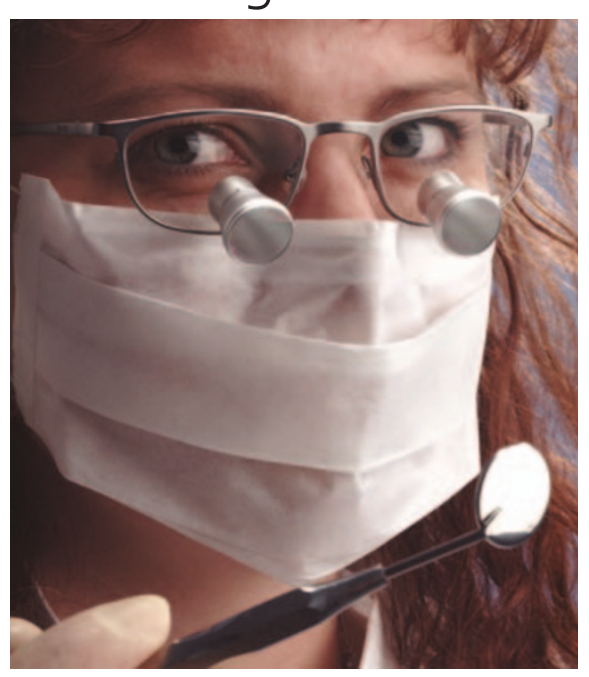

Carl Zeiss G2 Surgical Loupes are specifically designed for close magnification and are available in $300 \mathrm{~mm}, 350 \mathrm{~mm}, 400 \mathrm{~mm}$ and $500 \mathrm{~mm}$ working distance. During long procedures, comfort is essential, and in recognition of this each loupe weighs just $6 \mathrm{~g}$ for a lightweight maximum comfort fit that minimises fatigue.

Each G2 loupe construct is matched to the user's exact interpupillary distance. Trained staff can take all of the necessary measurements on site to ensure a perfect fit and perfect clarity. The loupe can be fitted to plano or prescription lenses fitted into titanium frames which are available in a silver or gold finish and are available in three sizes: small, medium or large. They are available from Nuview. Reader response number $\mathbf{6 1}$

\section{Integrated system}

R4 practice management system from Kodak Dental Systems is a dental practice management system. Built on an open database and written using the most modern tools available, the system is ideal contour of the root, allowing the instrugain deeper access.

bide tips so they stay sharper for longer and calculus removal on exposed root surfaces, when an ultrasonic scaler is uncomfortable he patient.

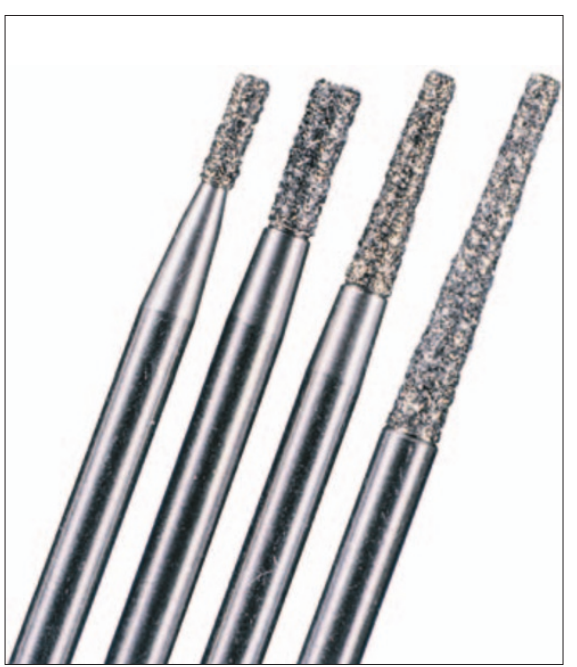

